\section{Galectin-9 reflects the interferon signature and correlates with disease activity in systemic autoimmune diseases. Response to: 'Biomarkers: to be or not to be' by Yavuz and Rönnblom}

With much interest, we read the comments ${ }^{1}$ of our colleagues Yavuz and Rönnblom regarding our manuscript on galectin- 9 as an easy to measure biomarker to detect the interferon (IFN) signature in patients with systemic lupus erythematosus (SLE) and antiphospholipid syndrome (APS). ${ }^{2}$ We thank them for their interest in our manuscript and their shared interest in the importance of the IFN signature in SLE and the subsequent need for more easily applicable markers to detect IFN activity. In the paper, we reported independently replicated correlations of galectin-9 with the IFN signature in patients with SLE and APS. The aim of our manuscript was to identify more easy to measure markers to detect the IFN signature. Besides serving as a marker for the IFN signature, we found that galectin-9 was elevated in patients with SLE and APS and correlated with signs of disease activity including SLEDAI.

We agree with the authors that the use of galectin-9 as a marker for IFN activity needs further confirmation before clinical implementation, and studies in which longitudinal samples and patients with different ethnic backgrounds are tested are among the next steps. Other candidates include the direct measurement of IFNs by digital ELISA, ${ }^{3}$ although these may only capture one subtype of IFN at a time. ${ }^{2}$ As galectin- 9 expression is induced by IFNs, galectin-9 is elevated in several (viral) infectious diseases and, similar to the IFN signature, may not be helpful in distinguishing (viral) infections from SLE disease activity, as discussed by Yavuz and Rönnblom.

Additionally, the authors mention a protective effect of galectin-9 administration in murine models of SLE. Indeed, recent studies in lupus-like animal models support a role for galectin-9 in the pathogenesis of SLE. ${ }^{4}$ Its effects in these animal models however are 'perplexing', 6 as the effects of a LGALS9 knock-out in pristane-induced lupus has opposite effects compared with galectin-9 administration in BXSB/MpJ and NZB/W F1 mice. ${ }^{4-6}$ Importantly, until our recent study, no data were available on galectin-9 levels in patients with SLE. Therefore, further studies to investigate the pathophysiological role of galectin-9 and studies in human patients with SLE are certainly relevant.

Besides SLE and APS, ${ }^{78}$ the IFN signature is present in several systemic autoimmune diseases including primary Sjögren's syndrome (pSS), systemic sclerosis and (juvenile) dermatomyositis (JDM). ${ }^{9-11}$ In this regard, elevated levels of galectin-9 have also been reported in patients with JDM, correlating with treatment-induced changes in disease activity in longitudinal samples. ${ }^{12}$ In addition, we found elevated levels of galectin- 9 in patients with pSS as compared with patients with nonSjögren sicca, correlating with disease activity as assessed by ESSDAI (EULAR Sjögren's Syndrome Disease Activity Index) and serum IgG levels (figure 1). Notably, in a randomised placebo-controlled trial in patients with $\mathrm{pSS},{ }^{13}$ we observed that successful disease inhibition by leflunomide/hydroxychloroquine combination therapy was associated with downregulation of galectin-9 levels (compared with no change in the placebo group) and changes in galectin-9 levels paralleled changes in markers of IFN activity, B-cell hyperactivity and disease activity (ESSDAI/ESSPRI) (manuscript in preparation). Therefore, serum levels of galectin- 9 are a promising marker to assess the IFN signature and correlate with changes in disease activity in patients with different autoimmune diseases.

Lucas $L$ van den Hoogen, ${ }^{1,2}$ Eefje $H$ M van der Heijden, ${ }^{1,2}$ Maarten R Hillen, ${ }^{1,2}$ Jorre S Mertens, ${ }^{1,2,3}$ Ruth D E Fritsch-Stork, ${ }^{4,5}$ Timothy R D J Radstake, ${ }^{1,2}$ Joel A G van Roon ${ }^{1,2}$

${ }^{1}$ Department of Rheumatology and Clinical Immunology, University Medical Center Utrecht, Utrecht University, Utrecht, The Netherlands

${ }^{2}$ Laboratory of Translational Immunology, University Medical Center Utrecht, Utrecht University, Utrecht, The Netherlands

${ }^{3}$ Department of Dermatology, Radboud University Medical Centre, Nijmegen, The Netherlands

${ }^{4} 1$ st Medical Department, Hanusch Hospital, Ludwig Boltzmann Institute of Osteology at the Hanusch Hospital of WGKK and AUVA Trauma Centre Meidling, Vienna, Austria

${ }^{5}$ Faculty of Medicine, Sigmund Freud Private University, Vienna, Austria

Correspondence to Dr Lucas $L$ van den Hoogen, Department of Rheumatology and Clinical Immunology, University Medical Center Utrecht, Utrecht University, Utrecht, GA 3508, The Netherlands; I.I.vandenhoogen@umcutrecht.nl

Handling editor Josef S Smolen

Contributors All authors contributed to the final draft of the manuscript.

Funding The authors have not declared a specific grant for this research from any funding agency in the public, commercial or not-for-profit sectors.
A

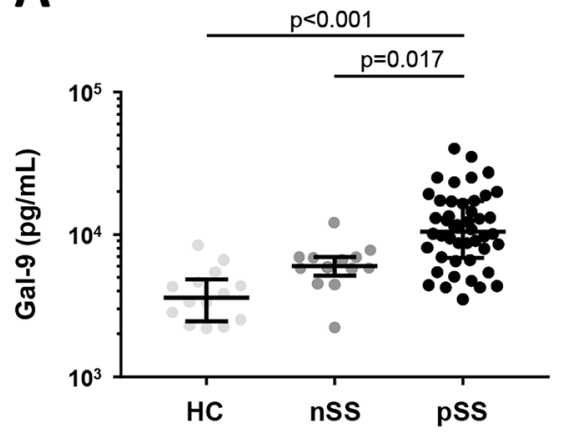

B

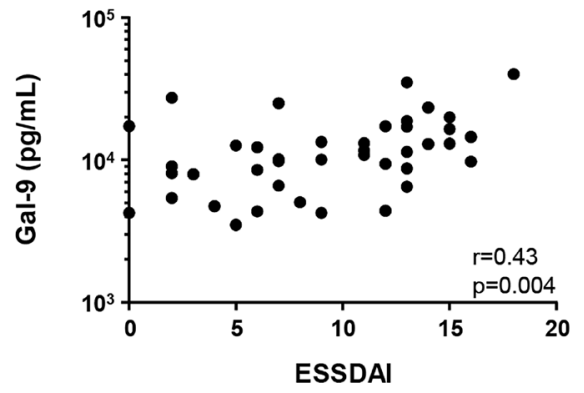

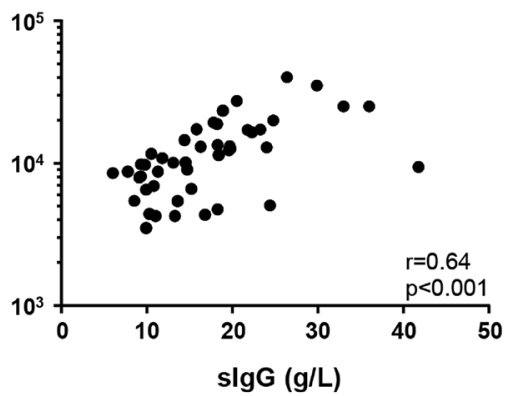

Figure 1 Increased circulating levels of galectin-9 in patients with pSS are associated with disease activity and serum IgG. Galectin-9 levels were measured in the serum of $\mathrm{HC}(n=14)$, patients with $n S S(n=13)$ and patients with pSS $(n=46)$ by Luminex multianalyte measurements. Patients with pSS had clearly increased circulating levels of Gal-9 compared with nSS and HC donors (A). In patients with pSS, serum Gal-9 levels correlated with ESSDAI and serum IgG (B). Differences between the groups were assessed using Kruskal-Wallis test with posthoc Dunn's multiple comparisons test, correlations were assessed using Spearman's correlation coefficient. ESSDAI, EULAR Sjögren's Syndrome Disease Activity Index; HC, healthy controls; nSS, non-Sjögren's sicca; pSS, primary Sjögren's syndrome. 
Competing interests None declared.

Patient consent for publication Obtained.

Ethics approval METC UMC Utrecht.

Provenance and peer review Commissioned; internally peer reviewed.

(C) Author(s) (or their employer(s)) 2020. No commercial re-use. See rights and permissions. Published by BMJ.

\section{D) Check for updates}

To cite van den Hoogen LL, van der Heijden EHM, Hillen MR, et al. Ann Rheum Dis 2020;79:e9.

Received 13 November 2018

Revised 21 November 2018

Accepted 25 November 2018

Published Online First 8 December 2018

\section{SLinked}

http://dx.doi.org/10.1136/annrheumdis-2018-214608

Ann Rheum Dis 2020;79:e9. doi:10.1136/annrheumdis-2018-214651

\section{REFERENCES}

1 Yavuz S, Rönnblom L. Biomarkers: to be or not to be. Ann Rheum Dis 2020;79:e8.

2 van den Hoogen LL, van Roon JAG, Mertens JS, et al. Galectin-9 is an easy to measure biomarker for the interferon signature in systemic lupus erythematosus and antiphospholipid syndrome. Ann Rheum Dis 2018;77:1810-4.
3 Rodero MP, Decalf J, Bondet V, et al. Detection of interferon alpha protein reveals differential levels and cellular sources in disease. J Exp Med 2017:214:1547-55.

4 Zeggar S, Watanabe KS, Teshigawara S. Lgals9 deficiency attenuates nephritis and arthritis in pristane-induced lupus model of BALB/c mice. Arthritis Rheumato 2018;70:1089-101

5 Panda SK, Facchinetti V, Voynova E, et al. Galectin-9 inhibits TLR7-mediated autoimmunity in murine lupus models. J Clin Invest 2018;128:1873-87.

6 Panda AK, Das BK. Perplexing role of galectin 9 in experimental lupus models: comment on the article by Zeggar et al. Arthritis Rheumatol 2018;70:1530-1.

7 van den Hoogen LL, Fritsch-Stork RD, Versnel MA, et al. Monocyte type I interferon signature in antiphospholipid syndrome is related to proinflammatory monocyte subsets, hydroxychloroquine and statin use. Ann Rheum Dis 2016;75:e81.

8 Baechler EC, Batliwalla FM, Karypis G, et al. Interferon-inducible gene expression signature in peripheral blood cells of patients with severe lupus. Proc Natl Acad Sci U SA 2003:100:2610-5.

9 Båve U, Nordmark G, Lövgren T, et al. Activation of the type I interferon system in primary Sjögren's syndrome: a possible etiopathogenic mechanism. Arthritis Rheum 2005;52:1185-95.

10 Eloranta ML, Franck-Larsson K, Lövgren T, et al. Type I interferon system activation and association with disease manifestations in systemic sclerosis. Ann Rheum Dis 2010;69:1396-402

11 Higgs BW, Liu Z, White B, et al. Patients with systemic lupus erythematosus, myositis, rheumatoid arthritis and scleroderma share activation of a common type I interferon pathway. Ann Rheum Dis 2011;70:2029-36.

12 Bellutti Enders F, van Wijk F, Scholman R, et al. Correlation of CXCL10, tumor necrosis factor receptor type $\mathrm{II}$, and galectin 9 with disease activity in juvenile dermatomyositis. Arthritis Rheumatol 2014;66:2281-9.

13 Radstake T, van der Heijden E, Moret F. Clinical efficacy of leflunomide/ hydroxychloroquine combination therapy in patients with primary sjogren's syndrome: results of a placebo-controlled double-blind randomized clinical trial. Arthritis Rheumato 2018:70. 